\title{
Breastfeeding: Insights for improving malaria, family planning, and maternal and child health outcomes in northwestern Nigeria through social and behavior change research
}

Breakthrough RESEARCH

Follow this and additional works at: https://knowledgecommons.popcouncil.org/departments_sbsr-rh

Part of the Health Communication Commons, and the Public Health Commons

How does access to this work benefit you? Let us know!

\section{Recommended Citation}

Breakthrough RESEARCH. 2020. "Breastfeeding: Insights for improving malaria, family planning, and maternal and child health outcomes in northwestern Nigeria through social and behavior change research," Programmatic Research Brief. Abuja: Population Council. 
Insights for improving malaria, family planning, and maternal and child health outcomes in northwestern Nigeria through social and behavior change research

\section{Breastfeeding}

This brief provides rigorous evidence-based insights to implementers and researchers of social and behavior change (SBC) programs that seek to improve community knowledge, attitudes, norms and behaviors for improved health of pregnant and postpartum women. The brief focuses on key behaviors including early breastfeeding initiation within one hour of birth and exclusive breastfeeding for the first six months of life, while also uncovering the barriers and facilitators to the practice of these positive health behaviors. It is one of a series that presents findings from a Breakthrough RESEARCH study that uniquely captures data on a wide range of psychosocial drivers of behavioral outcomes in the areas of family planning, malaria, and maternal, newborn and child health, and nutrition. The results presented in this series will inform the improvement of women's health in Nigeria and help to achieve the objectives of the Nigerian Reproductive Health Policy, ${ }^{1}$ as well as support global efforts to achieve the United Nations Sustainable Development Goals. ${ }^{2}$

\section{Breakthrough RESEARCH and Breakthrough ACTION in Nigeria}

Breakthrough RESEARCH and Breakthrough ACTION are USAID's flagship SBC programs. Breakthrough ACTION in Nigeria implements SBC programming in 11 states and the Federal Capital Territory (FCT) by targeting key psychosocial factors at multiple socioecological levels (e.g., individual, community, society) in order to improve health behaviors in the areas of malaria, family planning,

\section{KEY POINTS}

While nearly all women ever breastfed their youngest child, most women did not practice early and exclusive breastfeeding during the first six months. Low exclusive breastfeeding rates $(<10 \%)$ were clustered in southwestern Kebbi.

SBC programs should consider focusing on the widespread practice of giving non-breastmilk liquids in the first three days after birth, which is not recommended, and to dispel the myths that the first breast milk (colostrum) immediately after birth is "bad milk" and shouldn't be given to the child.

Among the most important psychosocial influences for breastfeeding were a woman's awareness of breastfeeding's benefits, timing, and her confidence to exclusively breastfeed.

ANC4+ attendance had a direct positive influence on initiating breastfeeding within one hour of birth, but not exclusive breastfeeding, which suggests that ANC is a promising channel for SBC programs to promote breastfeeding.

Women commonly cited their own and spousal opposition as the main reasons for not exclusively breastfeeding. Further qualitative research with spouses and family members is needed to explore the nature of this opposition in order to provide deeper insights for how SBC programs may address it. 
and maternal, newborn and child health plus nutrition $(\mathrm{MNCH}+\mathrm{N})$. Breakthrough RESEARCH in Nigeria conducts rigorous research to inform SBC program implementation in three of these program states (Kebbi, Sokoto, and Zamfara). Findings presented here are from a Breakthrough RESEARCH baseline study that will be used to inform SBC program adaption and scale-up in Nigeria.

\section{Setting the context}

Early and exclusive breastfeeding are critical behaviors for improving child survival and long-term health. It's wellestablished that immediately breastfeeding within one hour of birth lowers neonatal mortality risk, and exclusive breastfeeding for the first six months of life is critical for infants to achieve optimal growth, development, and health. ${ }^{3}$ However, in 2018, breastfeeding practices remained low with only 32 percent of children breastfed within one hour of birth in northwestern Nigeria and 29 percent exclusively breastfed for the first six months of life nationally, with likely lower rates in the northwestern region. ${ }^{4}$ Previous qualitative research from northwestern Nigeria suggests that barriers to appropriate breastfeeding include perceptions that colostrum is not pure and potentially harmful to the newborn. ${ }^{5}$ Water is often given to newborns, and solid foods are commonly introduced too early. Studies further indicate that early and exclusive breastfeeding practices are associated with wealth, maternal education, antenatal care attendance, facility delivery, and longer birth intervals. ${ }^{6-8}$

Factors including knowledge, norms, values, self-efficacy, and other influences may interact to spur healthy behaviors. ${ }^{9-11}$ This research brief aims to describe different barriers to early and exclusive breastfeeding practices, quantify the importance of ideational factors on these key behaviors, and model the extent to which SBC programs may effectively change breastfeeding behaviors by targeting identified psychosocial influences.

\section{Study methods}

Results are based on the behavioral sentinel surveillance (BSS) baseline survey that was conducted between September and October 2019 in Breakthrough ACTION program areas in Kebbi, Sokoto, and Zamfara. Figure 1 summarizes the study methods.

\section{FIGURE 1 BSS BASELINE SURVEY STUDY METHODS}

Study Pregnant women and women with under-2s population living within Breakthrough ACTION program ह है। areas in Kebbi, Sokoto andd Zamfara states (not representative at state level)

Study

design

Yy

Cross-sectional and cohort components

Sample

size

?

$\overbrace{2}$

3,032 pregnant women

3,043 women with a child under 2 years

Sampling 108 wards across 3 states

method

요용 $\because 0$

Census of pregnant women

Random selection of women with a child under 2 years

Data Mixed-effects logistic regression models were analysis used to derive predicted probabilities for ANC4+ (four or more visits) and facility-based delivery, controlling for pregnancy-related ideations and sociodemographic characteristics, including household wealth, age, education (woman and spouse), and employment (woman and spouse).

\section{Key results}

\section{Low and geographically clustered breastfeeding practices}

- While nearly all women reported ever breastfeeding their youngest child, only 42 percent initiated breastfeeding within one hour of birth, and only 38 percent of infants exclusively breastfed for the first six months of life. The widespread practice of giving non-breastmilk liquids to newborns in the first three days after birth contributes to low exclusive breastfeeding rates in this region and particularly southwestern Kebbi (Figure 2 and Map 1). 


\section{Programmatic implications}

$\checkmark$ Geographic tailoring of SBC messaging and activities locally is important. More research is needed to understand reasons for the geographic clustering of low exclusive breastfeeding rates in southwestern Kebbi.

$\checkmark$ SBC programs should consider focusing on early breastfeeding practices as this will address the widespread practice of giving non-breastmilk liquids in the first three days after birth and to dispel myths that the first breast milk after birth is bad milk. A focus on provider behavior around breastfeeding promotion may also be needed.

\section{FIGURE 2 WHILE MOST CHILDREN WERE EVER BREASTFED, MOST DID NOT RECEIVE EARLY AND EXCLUSIVE BREASTFEEDING}

Percentage of last-born children under two years who were ever breastfed, breastfed within 1 hour of birth, or given non-breastmilk liquids within the first 3 days after birth; Percentage of infants $0-5$ months exclusively breastfed

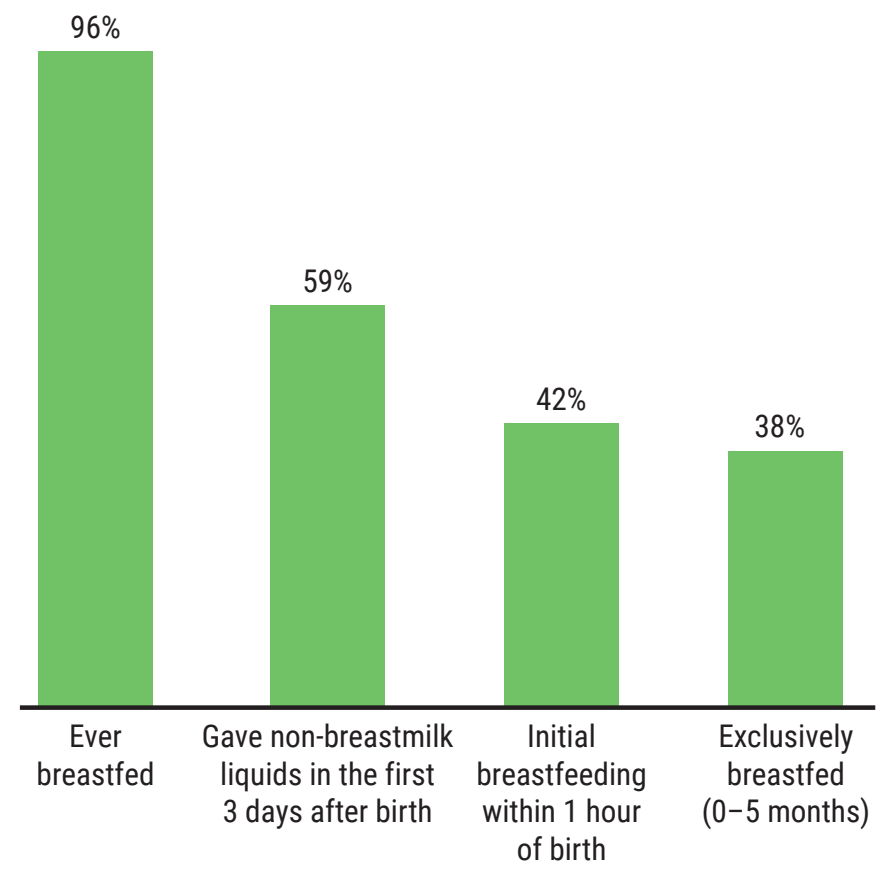

\section{MAP 1 LOW EXCLUSIVE BREASTFEEDING RATES} ARE CLUSTERED IN SOUTHWESTERN KEBBI

Exclusive breastfeeding* among children $0-5$ months by local government areas (LGA)

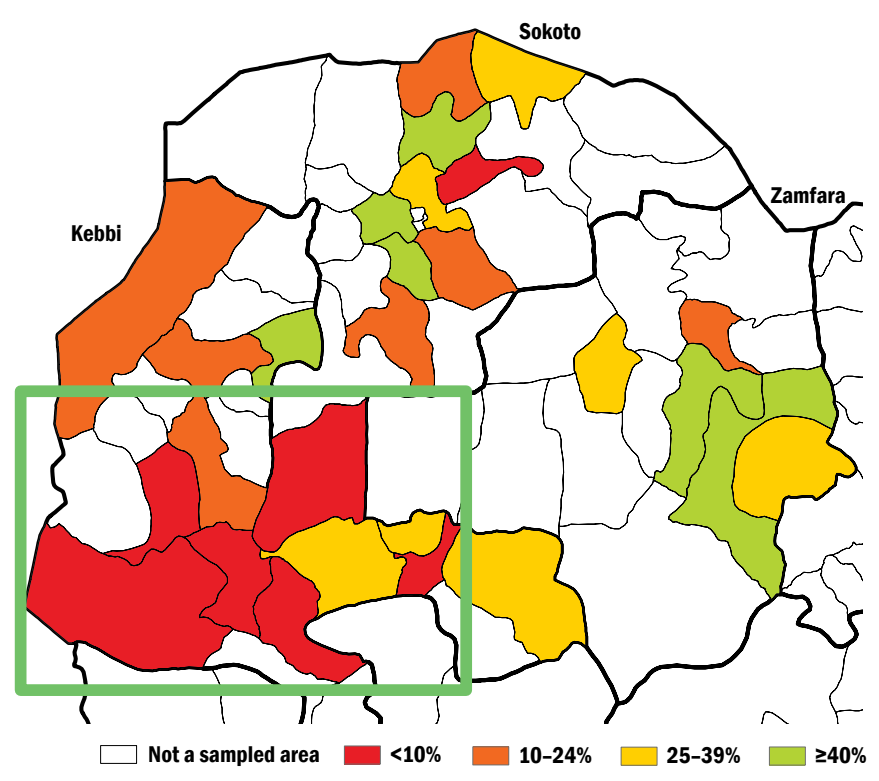

*Exclusive breastfeeding is defined in this study as infants aged $0-5$ months who are currently breastfed who were not given any solid or semi-solid foods in past 24 hours and who were not given any non-breastmilk liquids in the first 3 days after birth.

\section{Low awareness of benefits, common mispercep- tions, and personal opposition}

- Nearly half (48\%) of respondents were unsure or reported no benefits of breastfeeding to the mother. Almost two-thirds believed that women should breastfeed their child for 12-23 months, and only one in five (22\%) knew that women should breastfeed for two or more years.

- While most women (85\%) agreed that breastmilk contains essential nutrients for the first six months of life, about one in four (24\%) still believed that breastmilk immediately after birth is bad milk.

- When respondents were asked who influences their decision to breastfeed, 60 percent reported their spouse and 34 percent said no one else. Moreover, among women who did not exclusively breastfeed their youngest child, 74 percent cited their own or spousal opposition as the main reason (Table 1). Yet, in regression analyses controlling for other factors, we found no statistical association between spousal influence and breastfeeding behaviors despite women commonly citing spousal opposition as a main barrier (Figure 3). 
TABLE 1 PERSONAL AND SPOUSAL OPPOSITION MAIN STATED REASONS FOR NOT EXCLUSIVELY BREASTFEEDING

Among women who did not exclusively breastfeed her youngest child $(n=1,903)$, percentage who cited certain reasons for not exclusively breastfeeding

\begin{tabular}{|lc|}
\hline & $\%$ \\
\hline Respondent opposition & 40 \\
Spousal opposition & 34 \\
Not necessary & 21 \\
Inadequate milk & 16 \\
Fatalism (It's Up to God) & 12 \\
Religious or community leader opposition & 4 \\
Painful breastfeeding & 1 \\
\hline
\end{tabular}

Raising awareness about breastfeeding's benefits, timing, and efficacy are potentially important ways to promote breastfeeding (Figure 4)

- Women who knew at least one breastfeeding benefit were 1.5 times as likely to exclusively breastfeed than those who did not.

- Women who knew that six months is the ideal age to introduce complementary foods with breastmilk were 1.4 times as likely to exclusively breastfeed.

- Women who knew that initiating breastfeeding within one hour of birth protects a newborn were 1.2 and 1.4 times as likely to initiate breastfeeding within one hour of birth and to exclusively breastfeed, respectively.

\section{Programmatic implications}

$\checkmark$ SBC programs should emphasize breastfeeding's benefits to both mothers and newborns and ensure mothers know how long to breastfeed and when to introduce complementary foods. Such awareness could help reduce personal and spousal opposition to exclusive breastfeeding that was reported as main barriers to exclusive breastfeeding.

\section{FIGURE 3 BREASTFEEDING-RELATED IDEATIONS ASSOCIATED WITH INITIATION OF BREASTFEEDING WITHIN 1 HOUR OF BIRTH}

Predicted probabilities* of early breastfeeding initiation among last-born children under 2 years by ideational factor
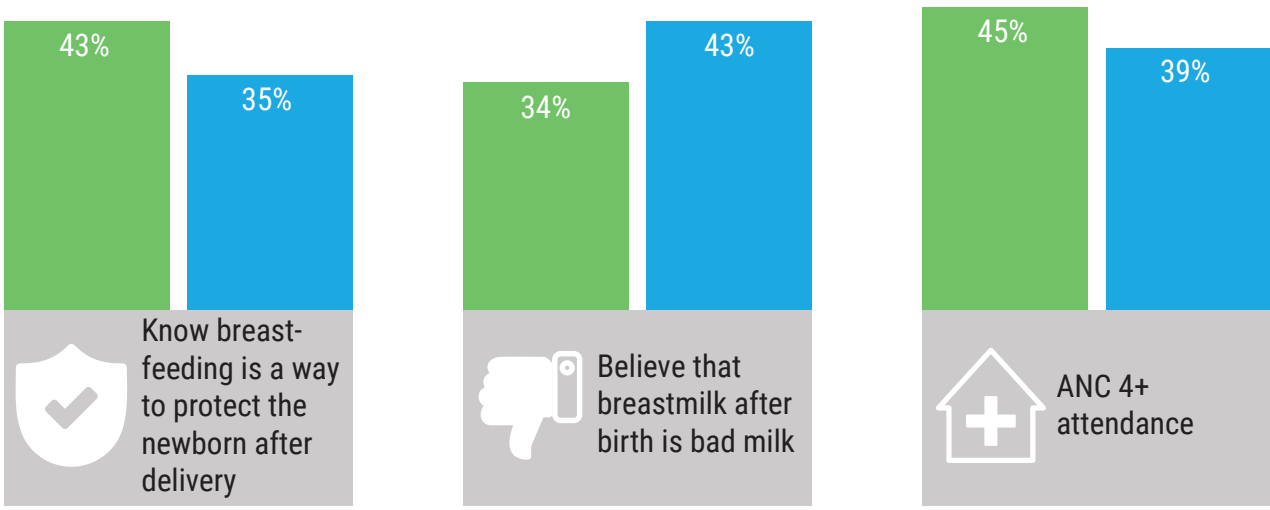

*Predicted probabilities of early breastfeeding initiation were derived from mixed-effects logistic regression models adjusted for breastfeeding-related ideations (Annex 1) and socioeconomic characteristics including household wealth, woman's age, education (woman and spouse), and employment (woman and spouse). All ideations presented were significant at the $<0.05$ level. 


\section{FIGURE 4 BREASTFEEDING-RELATED IDEATIONS ASSOCIATED WITH EXCLUSIVE BREASTFEEDING FOR THE FIRST 6 MONTHS OF LIFE}

Predicted probabilities* of exclusive breastfeeding** among infants aged 0-5 months by ideational factor

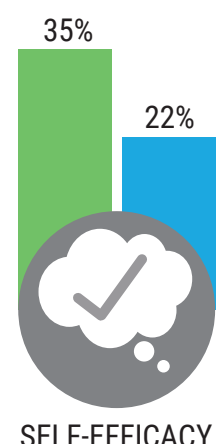

Confident to practice exclusive breastfeeding for first 6 months of infant's life
Yes No

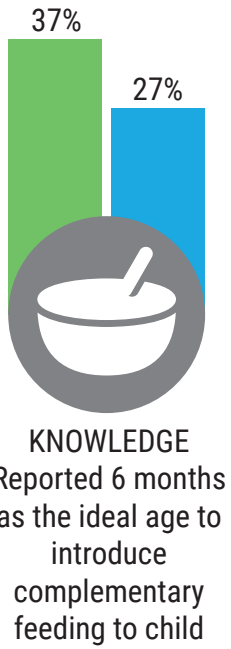

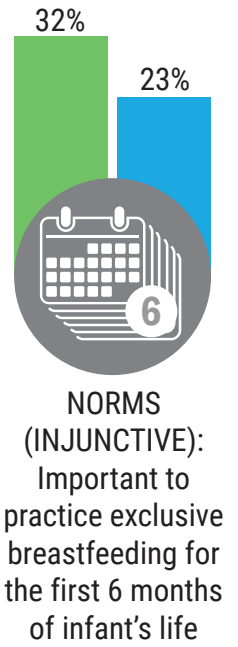

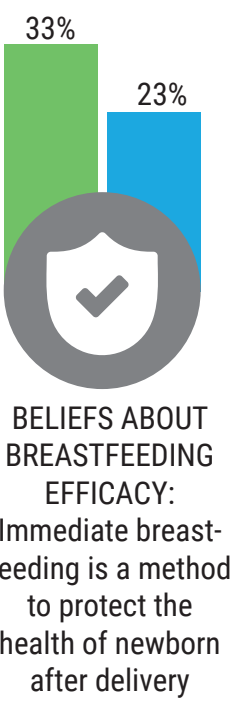

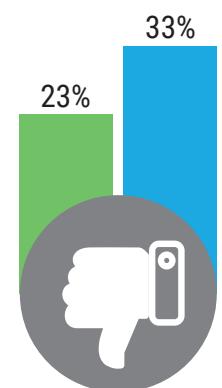

BELIEFS ABOUT BREASTFEEDING EFFICACY: Mother's breastmilk after delivery is bad milk

*Predicted probabilities of exclusive breastfeeding were derived from mixed-effects logistic regression models adjusted for breastfeeding-related ideations (Annex 1) and socioeconomic characteristics including household wealth, woman's age, education (woman and spouse), and employment (woman and spouse). All ideations presented were significant at the $<0.05$ level.

**Exclusive breastfeeding is defined in this study as infants aged $0-5$ months who are currently breastfed who were not given any solid or semi-solid foods in past 24 hours and who were not given any non-breastmilk liquids in the first 3 days after birth

\section{Reinforcing correct beliefs, antenatal care at- tendance, and mother's confidence also matters for breastfeeding promotion}

- Women who believed that breastmilk immediately after birth (colostrum) is "bad milk" were 1.3 and 1.5 times less likely to initiate breastfeeding within one hour of birth and to exclusively breastfeed, respectively, than those who did not hold that belief.

- Women who felt confident that they could exclusively breastfeed their child for the first six months of life were 1.6 times as likely to do so than those who felt uncertain about their abilities to do so.

- Women who cited health providers as influencing their decision to breastfeed were 1.9 times more likely to exclusively breastfeed for the first six months of life than those without health provider support.

- Antenatal care may provide an important opportunity for stressing the benefits of early and exclusive breastfeeding. Women who attended antenatal care at least four times (ANC4+) were 1.2 times as likely to initiate breastfeeding within one hour of birth, while there was no significant relationship between ANC4+ and exclusive breastfeeding.
- Sociodemographic factors were not related to exclusive breastfeeding although wealth and maternal employment were significantly associated with early breastfeeding initiation.

\section{Programmatic implications}

$\checkmark$ Knowledge alone will not raise breastfeeding rates. SBC programs must also focus on dispelling myths that breastmilk after birth is bad milk and help women build confidence to exclusively breastfeed for the first six months of life. More research is needed to understand the types of interventions that could support women's confidence to optimally breastfeed their infant.

$\checkmark$ Antenatal care visits may be an important moment to address the psychosocial factors that inhibit early and exclusive breastfeeding practices. Engaging religious and community leaders, such as through Breakthrough ACTION's Advocacy Core Group Model, could also help shift norms around entrenched, cultural breastfeeding practices, and perceptions. 


\section{What is the potential contribution of SBC programs?}

To estimate what SBC programs could potentially achieve in the absence of other changes (e.g., if the cost of services or other factors remain at their current levels), we conducted regression analyses assuming hypothetical scenarios in which every woman is confident that she can exclusively breastfeed, knows the benefits, timing and efficacy of exclusive breastfeeding, and does not believe that colostrum is bad milk (conceptualized as "perfect ideation").
Figure 5 presents actual exclusive breastfeeding rates compared to results of simulations that predict exclusive breastfeeding assuming "perfect ideation, by wealth quintile. In the "perfect ideation" scenario, we assume the SBC program resulted in all women recalling any benefits of breastfeeding, knowing when to introduce complementary foods, knowing that immediate breastfeeding within one hour of birth is a way to protect the newborn, feeling confident to exclusively breastfeed, believing it's important to exclusively breastfeed, and holding no misperceptions about colostrum as bad milk. In this scenario, exclusive breastfeeding could potentially increase from 38 percent to 66 percent-or a 74 percent relative increase from current levels in absence of other changes.

\section{FIGURE 5 SIMULATION OF THE POTENTIAL EFFECTS OF "PERFECT IDEATION" ON EXCLUSIVE BREASTFEEDING BY WEALTH QUINTILES}

Predicted probabilities* of exclusive breastfeeding** among children aged 0-5 months if all psychosocial influences significantly associated with exclusive breastfeeding are assumed to be positive ("perfect ideation")

Predicted probabilities of exclusive breastfeeding at actual ideational levels

Predicted probabilities of exclusive breastfeeding with "perfect ideation"

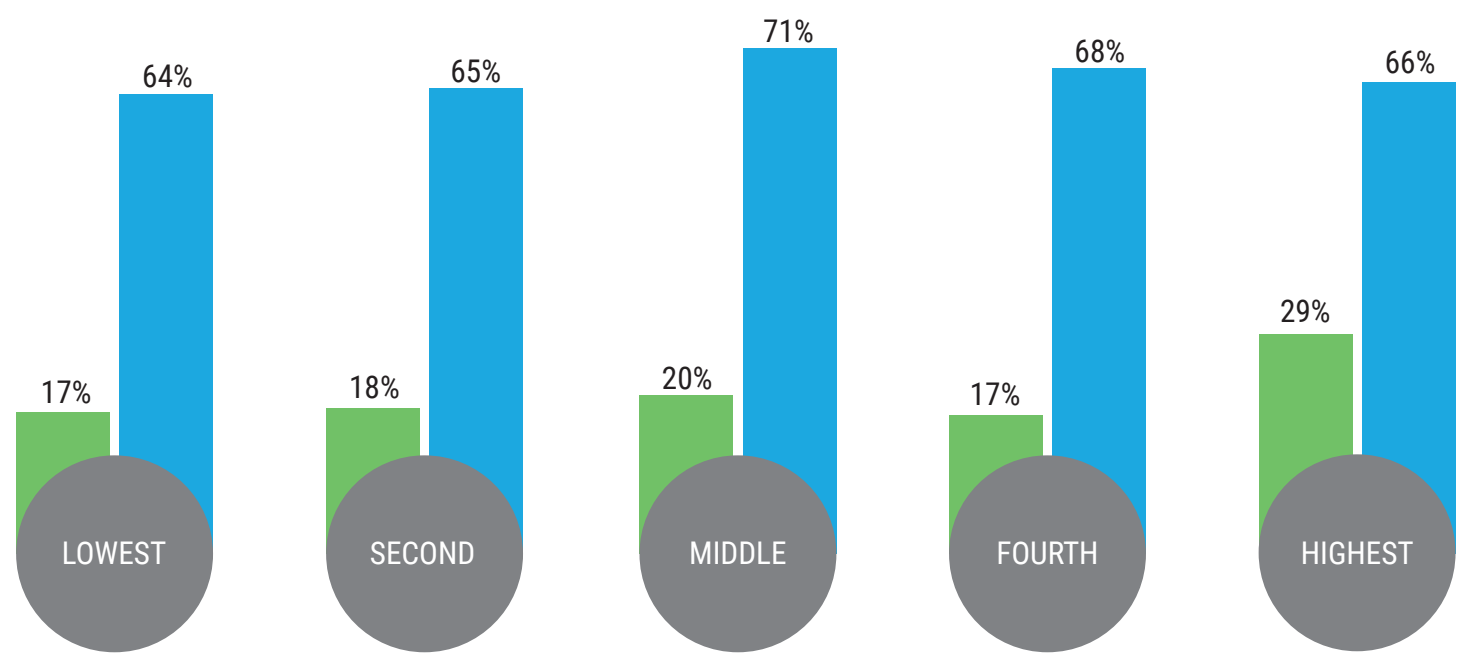

\footnotetext{
*Predicted probabilities of exclusive breastfeeding were derived from mixed-effects logistic regression models adjusted for breastfeeding-related ideations (Table 1) and socioeconomic characteristics including household wealth, woman's age, woman's regular attendance to community events, child's sex, ANC4+ attendance, facility-based delivery, education (woman and spouse), and employment (woman and spouse). All significant ideational metrics significant at the <0.05 level were assumed to equal 1 to derive predicted probabilities for the "perfect ideation" scenario (or zero in cases of negative ideational influences).

** Exclusive breastfeeding is defined in this study as infants aged 0-5 months who are currently breastfed who were not given any solid or semi-solid foods in past 24 hours and who were not given any non-breastmilk liquids in the first 3 days after birth
} 


\section{Conclusions}

The results indicate an important role for SBC programming in northwestern Nigerian and its potential to achieve substantial improvements in breastfeeding practices, even in the absence of other changes. To this end, findings point to the most important ideations for SBC programs to address in order to better target their activities that will lead to improved breastfeeding behaviors.

Women's knowledge about breastfeeding's benefits, timing, and efficacy were some of the most important ideations for increasing uptake of early and exclusive breastfeeding practices. Yet knowledge alone is not sufficient. Beliefs that immediate breast milk after birth is bad milk significantly reduced appropriate breastfeeding behaviors. Women must also feel confident to exclusively breastfeed for the first six months of life in order to do so. ANC4+ was also associated with early initiation but not with exclusive breastfeeding. This may demonstrate the importance of SBC programs targeting providers to improve the quality and content of breastfeeding as a topic during health talks at ANC visits. Unlike other health behaviors, social influences such as spousal support were not related to breastfeeding practices despite women commonly citing spousal opposition as a main reason for not breastfeeding.

Simulations further suggest that SBC programs alone could potentially increase exclusive breastfeeding rates from the current 33 percent to 66 percent in northwestern Nigeria if they were successful in changing identified breastfeeding ideations in all women. Although it is not expected that SBC programs will be able to achieve "perfect ideation," the simulations indicate what SBC programs could achieve in the absence of other changes.

\section{Annex 1 Breastfeeding-related ideational metrics}

\section{DIMENSION DOMAIN QUESTION OR LIKERT-SCALE STATEMENT}

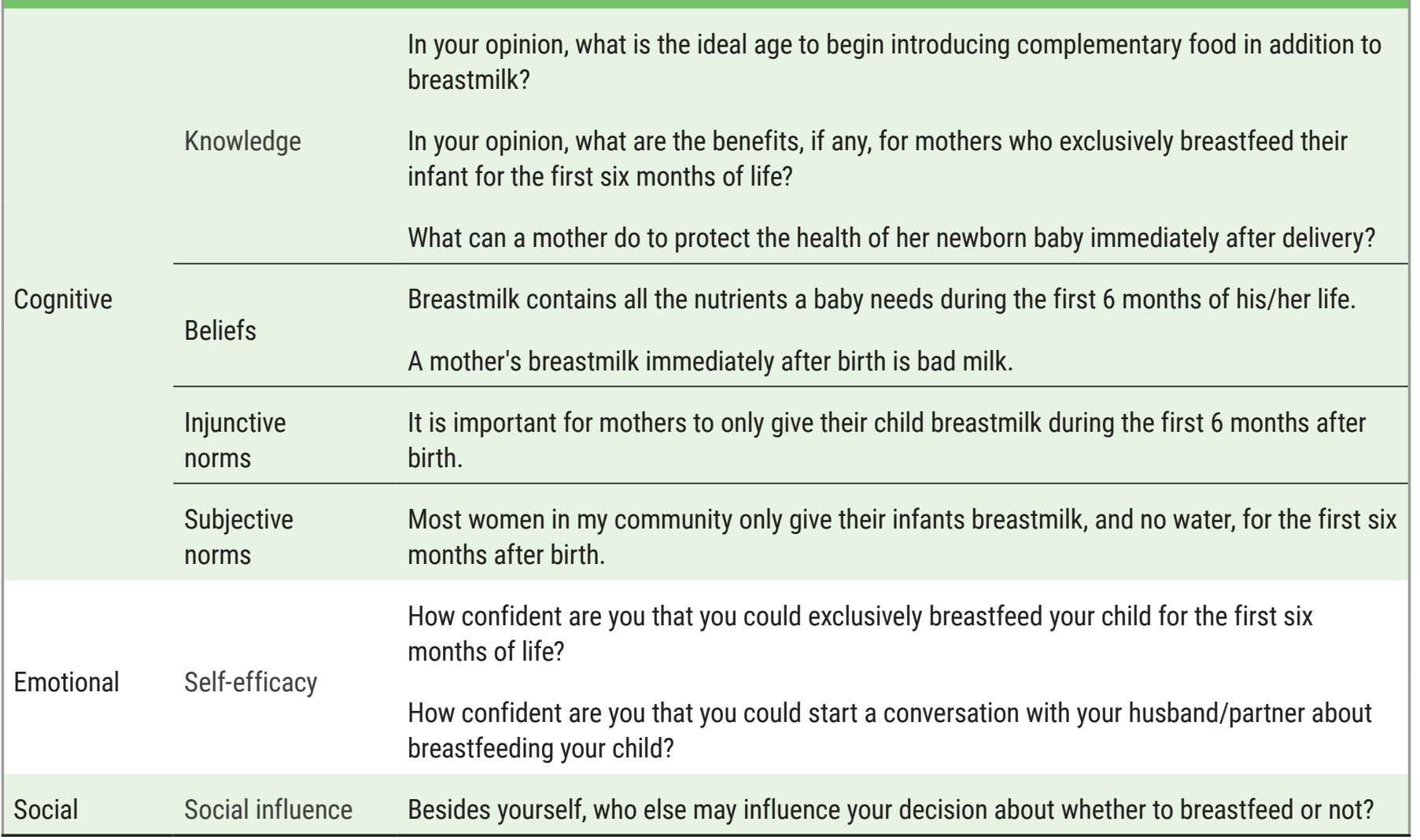




\section{References}

1. Federal Government of Nigeria. 2019. National Strategic Health Development Plan II (NSHDP) 2018-2022. Abuja: Nigeria: Federal Government of Nigeria.

2. Government of Nigeria. 2017. Implementation of the SDGs: A National Voluntary Review, Abuja FCT, Nigeria.

3. UNICEF and WHO. 2018. "Capture the moment-early initiation of breastfeeding: the best start for every newborn." New York: UNICEF.

4. National Population Commission (NPC) and ICF International. 2019. Nigeria Demographic and Health Survey 2018. Abuja, Nigeria and Rockville, MD, USA: NPC an ICF.

5. Uche, M.O., A. S. Umar, and H. Ahmed. 2011. "Knowledge and practice of exclusive breastfeeding in Kware, Nigeria," $A f$ rican Health Sciences 11(3): 518-23.

6. Agho, K. E. et al. 2011. "Determinants of exclusive breastfeeding in Nigeria," BMC Pregnancy and Childbirth 11. doi: 10.1186/1471-2393-11-2

7. Ogbo, F. A., K. E. Agho, and A. Page. 2015. "Determinants of suboptimal breastfeeding practices in Nigeria: evidence from the 2008 demographic and health survey," BMC Public Health 15. doi: 10.1186/s12889-015-1595-7

8. Berde, A. S. and S. S. Yalcin. 2016. "Determinants of early initiation of breastfeeding in Nigeria: a population-based study using the 2013 demograhic and health survey data." BMC Pregnancy and Childbirth 16: 32. doi: 10.1186/s12884016-0818-y

9. Bai, Y. K., S. Lee, and K. Overgaard. 2019. "Critical review of theory use in breastfeeding interventions," Journal of Human Lactation 35(3): 478-500. doi: 10.1177/0890334419850822

10. Kincaid, DL. 2000. "Mass media, ideation, and behavior: a longitudinal analysis of contraceptive change in the Philippines," Communication Research 27(6): 723-763. doi: 10.1177/009365000027006003

11. Krenn, S. et al. 2014. "Using behavior change communication to lead a comprehensive family planning program: the Nigerian Urban Reproductive Health Initiative," Global

\section{Acknowledgments}

This programmatic research brief describes work led by Tulane University under Breakthrough RESEARCH. This brief and the work it describes is possible through the work and support of the Center for Research, Evaluation Resources and Development (CRERD), Breakthrough ACTION in Nigeria, Population Reference Bureau, and Population Council in Washington, DC.

\section{Suggested citation}

Breakthrough RESEARCH. 2020. "Breastfeeding-Insights for improving malaria, family planning, and maternal and child health outcomes in northwestern Nigeria through social and behavior change programming," Programmatic Research Brief. Abuja, Nigeria: Population Council.

C 2020 The Population Council. All rights reserved.

\section{Email}

BreakthroughResearch@popcouncil.org

\section{Breakthrough RESEARCH | Population Council}

Plot 839 Idris Ibrahim Crescent | Jabi, Abuja, Nigeria +2348067787750

4301 Connecticut Ave., NW, Suite 280 | Washington, DC 20008 +12022379400 | breakthroughactionandresearch.org

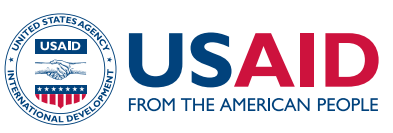

Breakthrough RESEARCH is made possible by the generous support of the American people through the United States Agency for International Development (USAID) under the terms of cooperative agreement no. AIDOAA-A-17-00018. The contents of this document are the sole responsibility of Breakthrough RESEARCH and Population Council and do not necessarily reflect the views of USAID or the United States Government.
POPULATION COUNCIL

Ideas. Evidence. Impact.

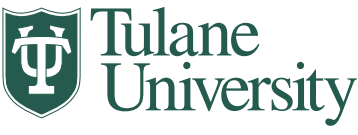

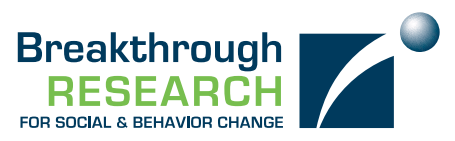

Our project turns evidence into action by providing thought provoking guidance to improve SBC policy and programming, with the goal of improving the cost-effectiveness of USAID's health and development strategies. Breakthrough RESEARCH catalyzes SBC by conducting state-of-the-art research and evaluation and promoting evidence-based solutions to improve health and development programs around the world. Breakthrough RESEARCH is a consortium led by the Population Council in partnership with Avenir Health, ideas42, Institute for Reproductive Health at Georgetown University, Population Reference Bureau, and Tulane University. 